\title{
Different Distribution of Cardiovascular Risk Factors According to Ethnicity: A Study in a High Risk Population
}

\author{
Fatima El Fakiri · Marc A. Bruijnzeels • \\ Marleen M. E. Foets · Arno W. Hoes
}

Published online: 16 May 2008

(C) The Author(s) 2008

\begin{abstract}
This study compares the distribution of cardiovascular risk factors in different ethnic groups at high risk of developing cardiovascular diseases within general practices. A total of 430 patients (179 Dutch, 126 Turks, 50 Surinamese, 23 Moroccans, 23 Antilleans and 29 from other ethnic groups) were included in the study. Data collection consisted of questionnaires and physical and clinical examinations. 54\% was female. The mean age was 53.1 (sd 9.9) years. There were important ethnic differences in the distribution of cardiovascular risk factors. Compared to the Dutch, ethnic minorities had significantly greater odds of being diabetic $(\mathrm{OR}=3.2-19.4)$; but were less likely to smoke $(\mathrm{OR}=0.10-0.53)$. Turkish individuals had a lower prevalence of hypercholesterolemia but were 2.4 times more likely to be obese than the Dutch. Hypertension was very common in all ethnic groups and no significant ethnic differences were found. These findings provide additional evidence of the need for tailored interventions for different ethnic groups in general practices.
\end{abstract}

Keywords Cardiovascular risk factors .

Ethnic minority groups - General practice .

Tailored intervention

F. El Fakiri $(\bowtie) \cdot$ M. M. E. Foets

Department of Health Policy and Management, Erasmus

Medical Centre Rotterdam, P.O. Box 1738, 3000 DR Rotterdam,

The Netherlands

e-mail: fatima.elfakiri@gmail.com

M. A. Bruijnzeels

Stichting Lijn 1 Haaglanden, Voorburg, The Netherlands

A. W. Hoes

Julius Centre for Health Sciences and Primary Care, University

Medical Centre Utrecht, Utrecht, The Netherlands

\section{Introduction}

People living in deprived neighbourhoods continue to be at greater risk for developing cardiovascular diseases (CVD) than the general population $[1,2]$. In the Netherlands, as in many European countries, people from ethnic minorities form a large group of all people living in the most deprived neighbourhoods. This group consists of Turks, Moroccans, Surinamese, Antilleans, and many others, with marked differences in cultural background, history and life style. Similar to other western countries such as the USA and UK [3-5] the overall cardiovascular mortality is generally higher among ethnic minority groups than in the general population [6].

Although several international studies have shown that both prevention through life style changes and improved treatment regimes play an important role in reducing cardiovascular diseases and related cardiovascular risk factors [7-10], the question rises whether ethnic specific interventions are more appropriate, since most studies have been conducted in white populations [11, 12] and the effectiveness of general interventions is disappointing in ethnic minority groups $[13,14]$. An important step in investigating whether interventions tailored to various ethnic minority groups are necessary to efficiently reduce cardiovascular risk, is the assessment and comparison of the cardiovascular risk profile of high-risk people from different ethnic backgrounds.

According to a systematic review of Uitewaal et al. [15] some major risk factors such as diabetes, smoking and obesity, are more prevalent among Turkish and Moroccan minorities than among the native Dutch population. Further information about the distribution of modifiable cardiovascular risk factors in individuals of different ethnic origins, is warranted. 
We conducted a study in a multi-ethnic population at high risk of developing CVD to identify ethnic specific cardiovascular risk factors within general practices.

\section{Methods}

Data were collected in 2003 from patients from three primary healthcare centres representing five general practices (18 general practitioners) situated in deprived neighbourhoods of two major Dutch cites: Rotterdam and The Hague. Area deprivation in the Netherlands is defined according to an index, based on income and number of people dependant on social benefits and level of urbanisation [16].

\section{Study Population}

We selected 1131 patients aged 30-70 years living in deprived neighbourhoods, with one or more registered cardiovascular risk factors (smoking, hypertension, hypercholesterolemia, diabetes mellitus, family history of CVD, or history of CVD) from the electronic GP medical records to participate in a randomised controlled trial to reduce cardiovascular risk. In total 536 patients signed informed consent for the trial. Reasons for exclusion were: not reached after repeated home visits $(n=193)$ and subject refusal to participate $(n=402)$. Main reasons for refusal were: not interested $(n=114)$, language problems $(n=72)$, treated by a specialist $(n=49)$, had no time $(n=45)$ and other reasons $(n=122)$ like planned to go abroad for longer than six months and being too ill to participate. Complete questionnaires and physical and biochemical measurements were available from 430 patients.

\section{Physical and Biochemical Measurements}

Participants underwent a limited physical examination including blood pressure, weight and height measurements, which took place at their home by trained research assistants. Systolic and diastolic blood pressures were measured with a validated automatic sphygmomanometer, with participants in sitting position and after they had been resting for at least $5 \mathrm{~min}$. The average of two measurements, taken with a 10 min interval was used for the analysis. Weight was measured with subjects wearing light clothes and no shoes; height was measured without shoes to the nearest $\mathrm{cm}$. The body mass index (BMI) was determined by dividing the weight in $\mathrm{kg}$ by the square of height in meters. Blood samples were taken at the laboratory to assess fasting glucose, HbAc1 and lipid profile (total and HDL cholesterol and triglycerides). LDL-cholesterol was calculated using the Friedewald formula.
Questionnaire

A research assistant interviewed participants in their preferred language at the participant's home. The questionnaire was translated from Dutch into Turkish and Moroccan Arabic. For other groups who speak and understand the Dutch language (very) well, we used the Dutch questionnaire. Where necessary (i.e. in case of some Antilleans and Surinamese from Hindustani origin) interviewers from the same ethnic background were involved.

We used a structured questionnaire that included questions on demographic and socioeconomic characteristics (educational level, income and working status), family and personal history of CVD, health behaviour (physical activity, diet, smoking and alcohol consumption) and medication use.

\section{Definitions of Ethnicity and Cardiovascular Risk} Factors

Ethnicity was defined according to the country of birth of the respondents. We considered five ethnic groups: indigenous Dutch, Turkish, Moroccan, Surinamese, and Antilleans. A sixth group comprised small numbers of individuals from different other origins.

The cardiovascular risk factors were defined as follows:

- Diabetes mellitus: was considered present if the measured fasting glucose $\geq 7.0 \mathrm{mmol} / 1$ [17]; and/or patients currently used diabetes medication.

- Hypertension: patients were considered as hypertensive if the systolic blood pressure was $\geq 140 \mathrm{~mm} \mathrm{Hg}$ and/or diastolic blood pressure was $\geq 90 \mathrm{~mm} \mathrm{Hg}$ [18] and/or currently used anti-hypertensive medications.

- Hypercholesterolemia was defined as total cholesterol $\geq 5.0 \mathrm{mmol} / 1$ [19]; and/or current use of lipid-lowering medication.

- Smoking behaviour: participants reported whether they smoked (current smokers) and if they had stopped whether they had smoked at least 100 cigarettes during their lifetime (ex-smokers) [20].

- Overweight and obesity: we classified participants as overweight in case of a BMI between $25 \mathrm{~kg} / \mathrm{m}^{2}$ and $30 \mathrm{~kg} / \mathrm{m}^{2}$ and as obese if their BMI was $\geq 30 \mathrm{~kg} / \mathrm{m}^{2}$ [21].

- 10-year absolute risk of developing CVD was determined using the Framingham risk function [22]. Two 10-year risk-thresholds were considered: $\geq 10 \%$ and $\geq 20 \%$.

Statistical Analysis

To compare the differences in cardiovascular risk factors between the six ethnic groups, we used Chi-square tests for 
categorical variables. Differences in continuous variables were assessed using one-way analysis of variance.

We examined the associations between ethnicity and cardiovascular risk factors and cardiovascular risk using multiple logistic regression analysis to adjust for differences in age and gender between the ethnic groups. We used SPSS software version 12.0 for data analysis.

Ethics

The study protocol was approved by the local ethics committee of the Erasmus Medical Centre of Rotterdam. All participants gave their informed consent to participate.

\section{Results}

The response rate was $47 \%$. There were no remarkable differences between responders and non-responders in background characteristics or known cardiovascular risk factors (Table 1). Responders were on average two years younger than non-responders (53. $2 \pm 9.7$ years versus $55.5 \pm 9.7$ years) and there were fewer diabetics among responders than among non-responders (31\% and 39\%).

In Table 2 we present the background characteristics of the various ethnic groups with completed risk profile. Large differences between the ethnic groups were present according to age, educational level and working status. All ethnic minority groups were on average four to eight years younger than Dutch people. A greater proportion of Moroccans than other ethnic groups had no school education. There were fewer employed individuals among the Turks and more retired people among the Dutch compared to the other ethnic groups.

The results of the clinical measurements showed that the levels of $\mathrm{HbAc1}$, fasting glucose and triglycerides were significantly different across the ethnic groups (Table 3 ). The diastolic, but not systolic blood pressure was significantly different according to ethnicity. There were significant differences in the BMI, with Turkish people having the highest BMI. The Dutch had the highest 10-year absolute risk to develop CVD.

Table 4 shows that there were important ethnic differences in the prevalence of diabetes, hypercholesterolemia, smoking behaviour and obesity. Moroccan individuals had the greatest proportion of diabetics (74\%) while the Dutch had the lowest proportion (17\%). The prevalence of hypercholesterolemia was highest in Dutch $(86 \%)$ and of obesity in the Turkish participants $(61 \%)$. There were more smokers among Dutch (41\%) than other ethnic groups. Further analysis of the gender difference in smoking behaviour showed that the greatest number of smokers were Turkish males and Dutch females (data not shown).
Table 1 Characteristics ${ }^{\mathrm{a}}$ of non-responders $(n=595)$, responders $(n=536)$ and responders with complete cardiovascular risk profile $(n=430)$

\begin{tabular}{|c|c|c|c|}
\hline & $\begin{array}{l}\text { Non- } \\
\text { responders } \\
(n=595)\end{array}$ & $\begin{array}{l}\text { Responders } \\
(n=536)\end{array}$ & $\begin{array}{l}\text { Complete CV } \\
\text { risk profile } \\
(n=430)\end{array}$ \\
\hline \multicolumn{4}{|l|}{ Gender } \\
\hline Males & $51^{\mathrm{a}}$ & 46 & 46 \\
\hline Females & 49 & 54 & 54 \\
\hline Age (mean (sd)) & $55.5(9.7)$ & $53.2(9.7)$ & $53.1(9.9)$ \\
\hline 30-39 years & 9 & 9 & 10 \\
\hline 40-49 years & 18 & 28 & 28 \\
\hline 50-59 years & 36 & 35 & 33 \\
\hline $60+$ years & 38 & 26 & 28 \\
\hline \multicolumn{4}{|l|}{ Ethnicity } \\
\hline Dutch & 38 & 40 & 42 \\
\hline Turkish & 22 & 27 & 29 \\
\hline Moroccan & 4 & 6 & 5 \\
\hline Surinamese & 12 & 12 & 12 \\
\hline Antillean & 2 & 5 & 5 \\
\hline Other & 22 & 10 & 8 \\
\hline \multicolumn{4}{|c|}{ Cardiovascular risk factors (based on data from GP records) } \\
\hline Diabetes & 39 & 31 & 29 \\
\hline Hypertension & 49 & 44 & 44 \\
\hline Hypercholesterolemia & 20 & 22 & 23 \\
\hline Smoking & 27 & 32 & 30 \\
\hline History of CVD & 33 & 31 & 32 \\
\hline $\begin{array}{l}\text { Family history of } \\
\text { CVD }\end{array}$ & 15 & 17 & 19 \\
\hline
\end{tabular}

${ }^{a}$ All values are proportions, unless stated otherwise

Hypertension was very common in all ethnic groups and no significant ethnic differences were found.

Ethnicity was a determinant of the age and gender adjusted prevalence of all investigated cardiovascular risk factors, except for hypertension and for the absolute risk for CVD (Table 5). Turks, Surinamese, Antilleans, and Moroccans had a clear increased risk of diabetes compared to the Dutch (odds ratios were 3.3, 6.7, 3.2, and 19.4 respectively). Obesity was clearly associated with a Turkish background: Turkish individuals were 2.4 times more likely to be obese than Dutch. All ethnic groups were less likely to smoke than the Dutch. Almost all non-Dutch ethnic groups had a lower prevalence of hypercholesterolemia than the Dutch, but this association was statistically significant for the Turks only. Although the Dutch had a higher 10-year CVD risk than ethnic minority groups, after adjusting for age and gender, most ethnic minority groups were more likely to have a 10 -year absolute cardiovascular risk $\geq 10 \%$ and $\geq 20 \%$ than the Dutch. However, this association was not statistically significant. 
Table 2 Demographic characteristics of the ethnic groups participating in the study $(n(\%))$

\begin{tabular}{|c|c|c|c|c|c|c|c|c|}
\hline & $\begin{array}{l}\text { Dutch } \\
n=179\end{array}$ & $\begin{array}{l}\text { Turkish } \\
n=126\end{array}$ & $\begin{array}{l}\text { Moroccan } \\
n=23\end{array}$ & $\begin{array}{l}\text { Surinamese } \\
n=50\end{array}$ & $\begin{array}{l}\text { Antillean } \\
n=23\end{array}$ & $\begin{array}{l}\text { Other } \\
n=29\end{array}$ & $\begin{array}{l}\text { Total } \\
n=430\end{array}$ & $\begin{array}{l}\text { Overall } \\
\text { significance }\end{array}$ \\
\hline Females & $88(49)$ & $76(60)$ & $15(65)$ & $29(58)$ & $15(65)$ & $9(31)$ & $232(54)$ & $P=0.028$ \\
\hline Age (mean $(\mathrm{sd}))$ & $57.5(8.7)$ & $48.8(9.3)$ & $49.5(10.3)$ & $51.7(9.0)$ & $52.2(8.0)$ & $53.0(8.5)$ & $53.1(9.9)$ & $P=0.0001$ \\
\hline \multicolumn{9}{|l|}{ Age categories } \\
\hline $30-39$ years & $6(3)$ & $24(19)$ & $4(17)$ & $6(12)$ & $2(9)$ & $2(7)$ & $44(10)$ & \multirow[t]{4}{*}{$P=0.0001$} \\
\hline $40-49$ years & $31(17)$ & $50(40)$ & $11(48)$ & $17(34)$ & $7(30)$ & $5(17)$ & $121(28)$ & \\
\hline $50-59$ years & $66(40)$ & $31(25)$ & $3(13)$ & $17(34)$ & $10(44)$ & $16(55)$ & $143(33)$ & \\
\hline $60+$ years & $76(43)$ & $21(17)$ & $5(22)$ & $10(20)$ & $4(17)$ & $6(21)$ & $122(28)$ & \\
\hline \multicolumn{9}{|c|}{ Highest educational level $^{\mathrm{a}}$} \\
\hline No & $16(10)$ & $39(32)$ & $17(74)$ & $7(15)$ & $3(14)$ & $4(17)$ & $86(21)$ & \multirow[t]{5}{*}{$P=0.0001$} \\
\hline Low & $63(38)$ & $62(51)$ & $2(9)$ & $13(27)$ & $3(14)$ & $8(33)$ & $151(37)$ & \\
\hline Lower secondary & $63(38)$ & $10(8)$ & $2(9)$ & $17(35)$ & $12(57)$ & $6(25)$ & $110(27)$ & \\
\hline Higher secondary & $13(8)$ & $8(7)$ & $0(0)$ & $8(17)$ & $2(10)$ & $5(21)$ & $36(9)$ & \\
\hline Higher & $13(9)$ & $3(3)$ & $2(9)$ & $3(6)$ & $1(5)$ & $1(4)$ & $22(5)$ & \\
\hline \multicolumn{9}{|l|}{ Working status } \\
\hline Employed & $62(35)$ & $21(17)$ & $8(35)$ & $22(44)$ & $13(57)$ & $10(35)$ & $136(32)$ & \multirow[t]{5}{*}{$P=0.0001$} \\
\hline Housewife/man & $43(24)$ & $58(46)$ & $12(52)$ & $14(28)$ & $5(22)$ & $6(21)$ & $138(32)$ & \\
\hline Retired & $42(24)$ & $7(6)$ & $2(9)$ & $3(6)$ & $0(0)$ & $2(7)$ & $56(13)$ & \\
\hline $\begin{array}{l}\text { Incapacitated for } \\
\text { work }\end{array}$ & $22(12)$ & $9(7)$ & $1(4)$ & $3(6)$ & $4(17)$ & $8(28)$ & $47(11)$ & \\
\hline Unemployed & $10(6)$ & $31(25)$ & $0(0)$ & $8(16)$ & $1(4)$ & $3(10)$ & $53(12)$ & \\
\hline $\begin{array}{l}\text { Public health care } \\
\text { insurance }^{\mathrm{b}}\end{array}$ & $153(86)$ & $116(95)$ & $23(100)$ & $44(88)$ & $19(86)$ & $27(93)$ & $382(90)$ & $P=0.054$ \\
\hline
\end{tabular}

Missing values: ${ }^{\mathrm{a}} 25,{ }^{\mathrm{b}} 5$

Table 3 Biochemical and physical characteristics of the study population by ethnicity (mean (sd))

\begin{tabular}{|c|c|c|c|c|c|c|c|c|}
\hline & $\begin{array}{l}\text { Dutch } \\
n=179\end{array}$ & $\begin{array}{l}\text { Turkish } \\
n=126\end{array}$ & $\begin{array}{l}\text { Moroccan } \\
n=23\end{array}$ & $\begin{array}{l}\text { Surinamese } \\
n=50\end{array}$ & $\begin{array}{l}\text { Antillean } \\
n=23\end{array}$ & $\begin{array}{l}\text { Other } \\
n=29\end{array}$ & $\begin{array}{l}\text { Total } \\
n=430\end{array}$ & $\begin{array}{l}\text { Overall } \\
\text { significance }\end{array}$ \\
\hline $\operatorname{HbAc1}(\%)$ & $6.1(0.9)$ & $6.4(1.4)$ & $7.7(1.8)$ & $7.2(1.9)$ & $6.7(1.5)$ & $6.5(1.1)$ & $6.5(1.4)$ & $P=0.0001$ \\
\hline Fasting glucose $(\mathrm{mmol} / \mathrm{l})$ & $6.1(2.0)$ & $6.4(2.2)$ & $8.8(3.8)$ & $7.6(3.2)$ & $6.6(2.1)$ & $6.8(2.2)$ & $6.6(2.4)$ & $P=0.0001$ \\
\hline Total cholesterol (mmol/l) & $5.6(1.0)$ & $5.4(1.0)$ & $5.4(0.8)$ & $5.2(0.9)$ & $5.7(1.2)$ & $5.7(1.4)$ & $5.5(1.0)$ & $P=0.083$ \\
\hline HDL-cholesterol (mmol/l) & $1.4(0.5)$ & $1.3(0.4)$ & $1.2(0.4)$ & $1.3(0.3)$ & $1.5(0.4)$ & $1.3(0.4)$ & $1.4(0.4)$ & $P=0.060$ \\
\hline LDL-cholesterol (mmol/l) & $3.4(0.9)$ & $3.2(0.9)$ & $3.1(0.9)$ & $3.2(0.8)$ & $3.6(1.0)$ & $3.4(1.4)$ & $3.3(1.0)$ & $P=0.362$ \\
\hline Triglycerides (mmol/l) & $1.8(1.1)$ & $2.0(1.2)$ & $2.2(1.9)$ & $1.6(0.7)$ & $1.5(0.6)$ & $2.1(1.5)$ & $1.9(1.2)$ & $P=0.037$ \\
\hline $\begin{array}{l}\text { Systolic blood pressure } \\
(\mathrm{mm} \mathrm{Hg})\end{array}$ & $142.5(23.4)$ & $139.8(22.9)$ & $145.3(23.5)$ & $149.3(27.0)$ & $142.8(20.3)$ & $136.9(26.7)$ & $142.3(23.9)$ & $P=0.186$ \\
\hline $\begin{array}{l}\text { Diastolic blood pressure } \\
\quad(\mathrm{mm} \mathrm{Hg})\end{array}$ & $84.3(11.3)$ & $87.4(11.9)$ & $91.3(14.1)$ & $90.9(12.9)$ & $87.2(11.6)$ & $83.4(15.5)$ & $86.4(12.4)$ & $P=0.002$ \\
\hline BMI $\left(\mathrm{kg} / \mathrm{m}^{2}\right)$ & $29.2(5.6)$ & $32.0(5.4)$ & $30.6(4.7)$ & $28.7(6.2)$ & $31.4(5.7)$ & $30.8(5.6)$ & $30.3(5.7)$ & $P=0.0001$ \\
\hline 10 -year CVD risk $(\%)$ & $21.6(13.7)$ & $14.5(11.5)$ & $15.8(12.3)$ & $17.2(11.2)$ & $14.9(7.8)$ & $17.6(10.2)$ & $18.0(12.6)$ & $P=0.0001$ \\
\hline
\end{tabular}

\section{Discussion}

Our results showed that individuals from ethnic minorities have a higher prevalence of diabetes and obesity but a lower prevalence of hypercholesterolemia and reported smoking than the native Dutch population, while the prevalence of hypertension seemed comparable between ethnic groups. Furthermore, in each ethnic group different combinations of cardiovascular risk factors were found.

The finding that diabetes was more prevalent among some ethnic groups than among the native population was also reported in other national and international 
Table 4 Prevalence of cardiovascular risk factors by ethnicity (n (\%))

\begin{tabular}{|c|c|c|c|c|c|c|c|c|}
\hline & $\begin{array}{l}\text { Dutch } \\
n=179\end{array}$ & $\begin{array}{l}\text { Turkish } \\
n=126\end{array}$ & $\begin{array}{l}\text { Moroccan } \\
n=23\end{array}$ & $\begin{array}{l}\text { Surinamese } \\
n=50\end{array}$ & $\begin{array}{l}\text { Antillean } \\
n=23\end{array}$ & $\begin{array}{l}\text { Other } \\
n=29\end{array}$ & $\begin{array}{l}\text { Total } \\
n=430\end{array}$ & $\begin{array}{l}\text { Overall } \\
\text { significance }\end{array}$ \\
\hline Diabetes & $30(17)$ & $42(33)$ & $17(74)$ & $26(52)$ & $8(35)$ & $8(28)$ & $131(31)$ & $P=0.0001$ \\
\hline Hypertension & $135(75)$ & $83(66)$ & $15(65)$ & $40(80)$ & $17(74)$ & $19(66)$ & $309(72)$ & $P=0.295$ \\
\hline Hypercholesterolemia & $154(86)$ & $90(71)$ & $16(70)$ & $40(80)$ & $20(87)$ & $19(66)$ & $339(79)$ & $P=0.011$ \\
\hline Current smokers & $79(44)$ & $43(34)$ & $2(9)$ & $9(18)$ & $6(26)$ & $9(31)$ & $148(34)$ & $P=0.001$ \\
\hline Ex-smoker & $66(37)$ & $25(20)$ & $3(13)$ & $13(26)$ & $6(26)$ & $13(49)$ & $126(29)$ & $P=0.004$ \\
\hline $\begin{array}{l}\text { Overweight } \\
\qquad\left(25 \leq \mathrm{BMI}<30 \mathrm{~kg} / \mathrm{m}^{2}\right)\end{array}$ & $72(41)$ & $38(31)$ & $9(39)$ & $18(38)$ & $5(23)$ & $9(33)$ & $151(36)$ & $P=0.380$ \\
\hline Obesity (BMI $\geq 30 \mathrm{~kg} / \mathrm{m}^{2}$ ) & $68(39)$ & $74(61)$ & $11(49)$ & $16(33)$ & $13(59)$ & $16(59)$ & $198(48)$ & $P=0.001$ \\
\hline 10 -year CVD risk $\geq 10 \%$ & $140(78)$ & $69(55)$ & $14(61)$ & $34(68)$ & $17(74)$ & $23(79)$ & $297(69)$ & $P=0.001$ \\
\hline 10 -year CVD risk $\geq 20 \%$ & $82(46)$ & $30(24)$ & $6(26)$ & $17(34)$ & $6(26)$ & $11(38)$ & $152(35)$ & $P=0.003$ \\
\hline
\end{tabular}

Table 5 Association of cardiovascular risk factors and 10 year absolute risk with ethnicity, adjusted for age and gender (odds ratio (OR) \& $95 \%$ confidence interval (CI))

\begin{tabular}{llllll}
\hline & $\begin{array}{l}\text { Turkish } \\
\text { OR }(95 \% \mathrm{CI})\end{array}$ & $\begin{array}{l}\text { Moroccan } \\
\text { OR }(95 \% \mathrm{CI})\end{array}$ & $\begin{array}{l}\text { Surinamese } \\
\text { OR }(95 \% \mathrm{CI})\end{array}$ & $\begin{array}{l}\text { Antillean } \\
\text { OR }(95 \% \mathrm{CI})\end{array}$ & $\begin{array}{l}\text { Other } \\
\text { OR }(95 \% \mathrm{CI})\end{array}$ \\
\hline Diabetes & $3.31(1.83-5.98) *$ & $19.35(6.71-55.82)^{*}$ & $6.67(3.28-13.57)^{*}$ & $3.24(1.24-8.49)^{*}$ & $2.11(0.84-5.31)$ \\
Hypertension & $1.07(0.61-1.87)$ & $1.01(0.38-2.71)$ & $1.92(0.86-4.31)$ & $1.27(0.46-3.54)$ & $0.79(0.33-1.89)$ \\
Hypercholesterolemia & $0.42(0.22-0.77) *$ & $0.37(0.14-1.02)$ & $0.66(0.29-1.50)$ & $1.07(0.29-3.91)$ & $0.33(0.14-0.81)^{*}$ \\
Smoking & $0.53(0.31-0.90) *$ & $0.10(0.02-0.45)^{*}$ & $0.23(0.10-0.52)^{*}$ & $0.41(0.15-1.12)$ & $0.42(0.18-1.00)$ \\
Obesity & $2.37(1.41-3.97)$ & $1.37(0.56-3.37)$ & $0.76(0.38-1.52)$ & $2.13(0.85-5.34)$ & $2.48(1.07-5.74)^{*}$ \\
10-year CVD risk $\geq 10 \%$ & $1.18(0.60-2.33)$ & $2.13(0.64-7.15)$ & $1.54(0.63-3.75)$ & $1.92(0.56-6.37)$ & $1.74(0.47-6.37)$ \\
10-year CVD risk $\geq 20 \%$ & $1.17(0.59-2.32)$ & $1.17(0.27-5.03)$ & $1.68(0.71-3.97)$ & $1.12(0.35-3.57)$ & $0.91(0.33-2.48)$ \\
\hline
\end{tabular}

* Statistically significant

epidemiological studies [15, 23-26]. In the studies by Cappucio et al. [23], Bhopal et al. [24], and Anand et al. [25], South Asians in the UK and Canada had a higher prevalence of diabetes/glucose intolerance than people of European origin; and in the study by Winkleby et al. [26] Black and Mexican American women had higher diabetes prevalence than white women. This phenomenon can be explained by genetic susceptibility and/or environmental factors such as the adoption of a western diet, obesity and physical inactivity [27].

We did not find indications for a higher prevalence of hypertension in ethnic minority people than in the Dutch population, although the diastolic blood pressure was relatively higher among ethnic minorities than among the Dutch. This result is similar to other studies showing no clear differences between Turkish or Moroccan people and the native Dutch population [15]. There are some indications of a higher prevalence among Surinamese (a mixed group of African descent and people originated from South Asia) than in Dutch [28], which is in accordance with international studies that reported a higher prevalence of hypertension in South Asians [29] and people from African origin [30] compared to white populations in the UK and USA respectively.

Hypercholesterolemia, based on the level of total cholesterol, was generally higher in Dutch than in most ethnic minority people. This is in line with the limited data comparing the Turkish or Moroccan ethnic groups with the Dutch [15] while no such information is available for $\mathrm{Su}$ rinamese and Antilleans. On the other hand, the levels of other lipid components were more disadvantageous (e.g. high levels of triglycerides among Turks and Moroccans) among some ethnic groups in our study than in the Dutch. In general, ethnic comparisons of the lipid profiles remain difficult because of the limited number of studies and inconsistencies of the findings [15].

In line with previous studies [15, 23, 24] obesity was more common among minority groups, particularly Turkish people, than in the native population. The proportion of obese individuals in our study also largely exceeded national rates implying that obesity is a serious health problem among people living in deprived 
neighbourhoods and in particular among ethnic minority women. Native Dutch had a higher prevalence of reported smoking than non-Dutch groups, but Turkish men had a higher prevalence than Dutch men. This is in agreement with other Dutch studies showing a high smoking prevalence among Turkish men [15]. The low prevalence of smoking among ethnic minority women in our study is also consistent with previous national and international studies [15, 23-25].

The 10-year cardiovascular risk was higher in Dutch, but the age and gender adjusted 10-year risk was somewhat higher in ethnic minorities, which could be attributed to their unfavourable cardiovascular risk factors. Intervention activities are recommended according to the 10-year CVD risk [19]. This approach could result in under treatment of young ethnic minority groups with high levels of (modifiable) risk factors and over treatment of elderly Dutch people [31].

Some limitations of the present study should be mentioned. First, the nature of the study population. Because data collection took place among a population at risk of developing CVD, this means that our results can not be generalised to the general population due the inclusion of high-risk individuals only. However, our findings point to the same direction as previous studies in the general population, and show the necessity of tailoring interventions also in this high-risk group. In addition, for the prevention of CVD, evidence has shown that targeting high-risk groups is more beneficial than targeting the general population [32]. The response rate was $47 \%$ which is satisfactory when taking into account previous studies conducted in multi-ethnic patient populations in the Netherlands [15]. We have no reason to believe that the cardiovascular risk factors are likely to be different in the individuals examined compared to those who were not because responders and non-responders in our study had a comparable cardiovascular risk profile according to GP medical records.

Since we firstly selected patients from the electronic GP medical records, our findings could be biased because of differences in access to the general practice or in the registration of risk factors between the general practitioners. Regarding access to the general practice, in the Netherlands (almost) all patients are registered in a general practice and therefore have equal access regardless of where they live. Concerning registration of risk factors, we used all available medical information from the GP medical records to identify potential high-risk patients. This yielded similar proportions of potentially high-risk individuals per general practitioner, indicating that an effect of differences in registration between the general practitioners is unlikely.
This study shows the heterogeneity of people living in deprived neighbourhoods in terms of ethnicity, demographic and socioeconomic characteristics, and particularly the distribution of cardiovascular risk factors which emphasizes the need for tailoring interventions to different ethnic groups at risk of developing CVD. Notably, attention should be given to diabetes intervention and education, since diabetes is one of the most prevalent cardiovascular risk factors among all ethnic minorities at risk of developing CVD, particularly the Moroccans. Among the Turks emphasis should be put on interventions aimed at reducing the high prevalence of obesity as well as smoking while among the Dutch hypercholesterolemia and smoking should be given higher priority than other risk factors. We found no ethnic differences in hypertension; however, taking into account previous studies we suggest that interventions with regard to Surinamese and Antilleans should take hypertension into consideration.

In conclusion, the present study shows that the different cardiovascular risk factors were not uniformly distributed among ethnic groups in the Netherlands and provides additional evidence of the need to tailor interventions for different ethnic groups in general practices.

Acknowledgments We would like to thank all patients and healthcare centers that participated in the study and research assistants for conducting the interviews. The study was financed by a grant of the Netherlands Organisation for Health Research and Development (Zon-Mw).

Open Access This article is distributed under the terms of the Creative Commons Attribution Noncommercial License which permits any noncommercial use, distribution, and reproduction in any medium, provided the original author(s) and source are credited.

\section{References}

1. Diez Roux AV, Merkin SS, Arnett D, et al. Neighbourhood of residence and incidence of coronary heart disease. N Engl J Med. 2001;345:99-106

2. Borrell LN, Diez Roux AV, Rose K, Catellier D, Clark BL. Atherosclerosis risk in communities study. Neighbourhood characteristics and mortality in the atherosclerosis risk in communities study. Int J Epidemiol. 2004;33:398-407.

3. Balarajan R. Ethnic differences in mortality from ischemic heart disease and cerebrovascular disease in England and Wales. BMJ. 1991;302:560-4.

4. Cooper R, Cutler J, Desvigne-Nickens P, et al. Trends and disparities in coronary heart diseases, stroke, and others cardiovascular diseases in the United States. Findings of the national conference on cardiovascular disease prevention. Circulation. 2000;26:3137-47.

5. Watkins LO. Perspectives on coronary heart disease in African Americans. Rev Cardiovasc Med. 2004;5(suppl 3):S3-13.

6. Bos V, Kunt AE, Keij-Deerenberg IM, Garssen J, Mackenbach J. Ethnic inequalities in age- and cause-specific mortality in the Netherlands. Int J Epidemiol. 2004;33:1-8. 
7. Cheung BM, Lauder IJ, Lau CP, Kumana CR. Meta-analysis of large randomized controlled trials to evaluate the impact of statins on cardiovascular outcomes. $\mathrm{Br} \mathrm{J}$ Clin Pharmacol. 2004;57:640-51.

8. Blood Pressure Lowering Treatment Trialists' Collaboration. Effects of different blood-pressure-lowering regimens on major cardiovascular events: results of prospectively designed overviews of randomised trials. Lancet. 2003;362:1527-35.

9. Kromhout D, Menotti A, Kesteloot H, Sans S. Prevention of coronary heart disease by diet and lifestyle: evidence from prospective cross-cultural, cohort, and intervention studies. Circulation. 2002;105:893-8.

10. Godtfredsen NS, Osler M, Vestbo J, Andersen I, Prescott E. Smoking reduction, smoking cessation, and incidence of fatal and non-fatal myocardial infarction in Denmark 1976-1998: a pooled cohort study. J Epidemiol Commun Health. 2003; 57:412-6.

11. Bartlett C, Davey P, Dieppe P, Doyal L, Ebrahim S, Egger M. Women, older persons, and ethnic minorities: factors associated with their inclusion in randomised trials of statins 1990-2001. Heart. 2003; 89:327-8.

12. Mason S, Hussain-Gambles M, Leese B, Atkin K, Brown J. Representation of South Asian people in randomised clinical trials: analysis of trials' data. BMJ. 2003;326:1244-5.

13. Cooper LA, Hill MN, Powe NR. Designing and evaluating interventions to eliminate racial and ethnic disparities in health care. J Gen Inter Med. 2002;6:477-86.

14. Massing MW, Foley KA, Carter-Edwards L, Sueta CA, Alexander CM, Simpson RJ Jr. Disparities in lipid management for African Americans and Caucasians with coronary artery disease: a national cross-sectional study. BMC Cardiovasc Disord. 2004; $4: 15$.

15. Uitewaal PJM, Manna DR, Bruijnzeels MA, Hoes AW, Thomas S. Prevalence of type 2 diabetes mellitus, other cardiovascular risk factors and cardiovascular disease in Turkish and Moroccan immigrants in North West Europe: a systematic review. Prev Med. 2004;39:1068-76.

16. Velden van der J, Rasch P, Reijneveld SA. [Identification of disadvantaged areas; a system for resource allocation to family practitioners] Ned Tijdschr Geneeskd. 1997;141:693-7.

17. WHO World Health Organization. Definition, diagnosis and classification of diabetes mellitus and its complications. Part I: diagnosis and classification. Geneva: World Health Organization, 1999.

18. Whitworth JA. World Health Organization, International Society of Hypertension Writing Group. 2003 WHO/ISH statement on management of hypertension. J Hypertens. 2003;21:1983-92.

19. CBO. Behandeling en preventie van coronaire hartziekten door verlaging van de plasmacholesterolconcentratie [treatment and prevention of CHD by lowering the plasma cholesterol concentration]; Consensus Cholesterol, tweede herziening. Alphen aan den Rijn: Van Zuiden Communications B.V. 1998.

20. World Health Organisation, Guidelines for controlling and monitoring the tobacco epidemic. Geneva: World Health Organization monograph nr. WM 290 98GU. 1998.

21. World Health Organisation. Obesity. Preventing and managing the global epidemic. Report of WHO consultation on obesity, 3-5 June 1997. Geneva: World Health Organisation; 1998.

22. Anderson KM, Odell PM, Wilson PWF, Kannel WB. Cardiovascular disease profiles. Am Heart J. 1990;121:283-98.

23. Cappuccio FP, Cook DG, Atkinson RW, Strazzullo P. Prevalence, detection, and management of cardiovascular risk factors in different ethnic groups in South London. Heart. 1997;78: 555-63.

24. Bhopal R, Unwin N, White M, et al. Heterogeneity of coronary heart disease risk factors in Indian, Pakistani, Bangladeshi, and European origin populations: cross sectional study. BMJ. 1999;319:215-20.

25. Anand SS, Yusuf S, Vuksan V, et al. Differences in risk factors, atherosclerosis, and cardiovascular disease between ethnic groups in Canada: the study of health assessment and risk in ethnic groups (SHARE). Lancet. 2000;356:279-84.

26. Winkleby MA, Kraemer HC, Ahn DK, Varady AN. Ethnic and socioeconomic differences in cardiovascular disease risk factors. Findings for women from the Third National Health and Nutrition Examination Survey, 1988-1994. JAMA. 1998;280:356-62.

27. Abate N, Chandalia M. The impact of ethnicity on type 2 diabetes. J Diabetes Complicat. 2003;17:39-58.

28. Bindraban NR, Stronks K, Klazinga NS. Cardiovasculaire risicofactoren bij Surinamers in Nederland: een literatuuroverzicht [Cardiovasculair risk factors for Surinamese in The Netherlands: a literature review]. Ned Tijdschr Geneeskd. 2003;147:1591-4.

29. Agyemang C, Bhopal R. Is the blood pressure of people South Asian in the UK higher or lower than that in European origin white people? A review of cross-sectional data. J Hum Hypertens. 2002;16:739-51.

30. Agyemang C, Bhopal R. Is the blood pressure of people from African origin adults in the UK higher or lower than that in European origin white people? A review of cross-sectional data. J Hum Hypertens. 2003; 17:523-34.

31. El Fakiri F, Bruijnzeels MA, Hoes AW. Prevention of cardiovascular diseases: focus on modifiable cardiovascular risk. Heart 2006;92:741-5.

32. Ebrahim S, Smith GD. Systematic review of randomised controlled trials of multiple risk factor interventions for preventing coronary heart disease. BMJ. 1997;314:1666-74. 